\title{
Children with severe OSAS who have adenotonsil- lectomy in the morning are less likely to have postoperative desaturation than those operated in the afternoon
}

\author{
[Les enfants atteints d'un SAOS sévère, opérés pour amygdalectomie le matin, sont \\ moins susceptibles de désaturation postopératoire que les opérés d’après-midi]
}

Albert Koomson MD, ${ }^{*}$ Isabelle Morin MSc, $\ddagger$ Robert Brouillette MD, $†$ Karen A. Brown MD*

Purpose: To determine, in a subset of children previously reported, if the time of day when adenotonsillectomy for severe obstructive sleep apnea syndrome (OSAS) was performed affected the incidence of postoperative respiratory complications.

Clinical features: Children having adenotonsillectomy were included if they had a polysomnographic diagnosis of severe OSAS within six months prior to operation. Patients who met the inclusion criteria were grouped by the occurrence of postoperative desaturation into a saturated (SAT) and desaturated (deSAT) group. The charts of children in group deSAT were reviewed. The clock time of the surgical procedure was recorded and categorized as morning (AM) or afternoon (PM).

Results: Eighty-eight patients met the inclusion criteria. There were $3 \mathrm{I}$ girls and 57 boys. The mean \pm SD age (yr) and weight $(\mathrm{kg})$ were $4.6 \pm 2.9 \mathrm{yr}$ and $20.8 \pm 14.5 \mathrm{~kg}$ respectively. There were 63 children in the SAT group and 25 in the deSAT group. Differences in age, weight and gender were not significant. The preoperative oxygen saturation $\left(\mathrm{SaO}_{2}\right)$ nadir for the SAT and deSAT groups was $80.8 \pm$ $10.2 \%$ and $67.6 \pm 17.5 \%(P<0.05)$ respectively. The preoperative obstructive apnea and hypopnea index was $15.8 \pm 10.2$ and $35.7 \pm 34.6$ events $\mathrm{hr}^{-1}(P<0.05)$, respectively. Surgery in 63 $(71.6 \%)$ children was performed in the AM. Univariate logistic regression identified $\mathrm{PM}$ surgery [odds ratio (OR) 4.6, 95\% confidence interval $(\mathrm{Cl})$ I.7 to $12.6, \mathrm{P}=0.002$ ] and a preoperative $\mathrm{SaO}_{2}$ nadir $<80 \%$ (OR 3.6, 95\% Cl I.4 to $9.4, P=0.009$ ) as risk factors predicting postadenotonsillectomy desaturation.

Conclusion: Children with severe OSAS whose surgery is performed in the AM are less likely to desaturate following adenotonsillectomy than children whose surgery is performed in the PM.
Objectif : Déterminer, chez un sous-groupe connu d'enfants, si l'heure à laquelle l'amygdalectomie a été réalisée pour un syndrome sévère d'apnée obstructive du sommeil (SAOS) a un effet sur l'incidence de complications respiratoires postopératoires.

Éléments cliniques : Des enfants subissant une amygdalectomie ont été inclus dans notre étude si un diagnostic polysomnographique de SAOS sévère avait été établi dans les six mois avant l'opération. Les patients admis ont été répartis selon l'occurrence de désaturation postopératoire dans un groupe de saturation (SAT) ou de désaturation (deSAT). Les dossiers des enfants du groupe deSAT ont été révisés. L'heure de l'opération a été notée sous matin (AM) ou après-midi (PM).

Résultats : Ont été admis à l'étude, 88 patients dont 31 filles et 57 garçons. La moyenne d'âge et de poids \pm l'écart type étaient respectivement de 4,6 $\pm 2,9$ ans et 20,8 $\pm 14,5 \mathrm{~kg}$. II y a eu 63 enfants dans le groupe SAT et 25 dans le groupe deSAT. Les différences d'âge, de poids et de sexe n'étaient pas significatives. Le niveau préopératoire minimal de saturation en oxygène $\left(\mathrm{SaO}_{2}\right)$ a été de $80,8 \pm 10,2 \%$ et de 67,6 $\pm 17,5 \%(P<0,05)$ dans les groupes SAT et deSAT respectivement. Les indices d'apnée obstructive et d'hypopnée préopératoires étaient de 15,8 \pm 10,2 et de 35,7 \pm 34,6 événements $\cdot h^{-1}(P<0,05)$, respectivement. L'opération de 63 (71,6\%) enfants s'est faite en AM. Une analyse univariée de régression logistique a considéré l'opération réalisée en PM [risque relatif (RR) de 4,6, intervalle de confiance (IC) de $95 \%$, $1,7$ à $12,6, P=0,002]$ et un niveau minimal de $\mathrm{SaO}_{2}$ préopératoire < $80 \%$ (RR de 3,6, IC de $95 \%$, I, 4 à 9,4, P = 0,009) comme des facteurs de risque prédictifs de désaturation postamygdalectomie.

Conclusion : Les enfants atteints d'un SAOS sévère, opérés en AM, sont moins susceptibles de subir une désaturation postamygdalectomie que les enfants opérés en PM.

From the Departments of Anesthesia, ${ }^{*}$ and Pediatrics, $†$ Montreal Children’s Hospital; and the Biostatistics Laboratory, $\ddagger$ McGill University Health Centre Research Institute, Montreal, Quebec, Canada.

Address correspondence to: Dr. Karen A. Brown, McGill University Health Centre/Montreal Children's Hospital, Division of Pediatric

Anesthesia, 2300 Tupper Street, Room C-1118, Montreal, Quebec H3H 1P3, Canada. Phone: 514-412-4463; Fax: 514-412-4341;

E-mail: roula.cacolyris@muhc.mcgill.ca

Accepted for publication April 23, 2003.

Revision accepted July 21, 2003. 
A

DENOTONSILLECTOMY is one of the commonest operations performed in children with the annual caseload in excess of a quarter million in the USA alone. ${ }^{1}$ In the UK about 2.3/1,000 children under the age of $12 \mathrm{yr}$ undergo tonsillectomy annually. ${ }^{2}$

Children with the obstructive sleep apnea syndrome (OSAS) have a higher risk for respiratory morbidity following adenotonsillectomy compared with the general pediatric population. ${ }^{3-5}$ Quality assurance programs have focused attention on patient characteristics contributing to postoperative risk. ${ }^{6}$ An evolving viewpoint emphasizes the need to look beyond the patient, to factors in the health delivery system per se, which may affect outcome. Newland et al. ${ }^{7}$ reported that surgery performed after 15:00 hr was associated with a higher risk for anesthetic-related cardiac arrest. Using our large database of children with OSAS who have undergone adenotonsillectomy, we aimed to assess the time of day of surgery as an independent risk factor for postadenotonsillectomy respiratory morbidity. A second aim was to examine the time interval between postoperative opioid administration and respiratory outcome.

\section{Methodology}

The study received Institutional approval.

\section{Patient selection criteria}

The selected patients represent a subset of children previously reported. ${ }^{5}$ The inclusion criteria were: 1) a sleep study documenting severe OSAS; 2 ) adenotonsillectomy within six months prior to surgery; and 3) extubation in the operating room at the end of surgery. The diagnostic criterion for severe OSAS was an abnormal sleep study defined, in our institution and elsewhere, ${ }^{8}$ by an obstructive apnea and hypopnea $(\mathrm{OAH})$ index $>5$ events $\cdot \mathrm{hr}^{-1}$.

\section{Chart review and study parameters} DIAGNOSTIC CRITERIA FOR OSAS

A diagnosis of OSAS was made with either polysomnography performed in the sleep laboratory or a cardiorespiratory sleep study performed in the home. Details of our sleep study recording systems have been published elsewhere. ${ }^{9-12}$ Although the studies were analyzed for several variables, ${ }^{5}$ only the $\mathrm{OAH}$ index and the preoperative saturation nadir $\left(\mathrm{preSaO}_{2}\right.$ nadir) are reported. The preSaO $\mathrm{S}_{2}$ nadir was defined as the minimum hemoglobin oxygen saturation regardless of duration and was validated by visual inspection of a computerized data record. ${ }^{10,13}$
POSTOPERATIVE CARE FOLLOWING ADENOTONSILLECTOMY

It is our practice to extubate children when awake in the operating room and to administer oxygen by facemask, attached to a Jackson Rees circuit, placed in close proximity to the child's face for the initial postoperative period. We administer iv morphine, in repeated doses $\left(0.05 \mathrm{mg} \cdot \mathrm{kg}^{-1}\right)$, as the opioid of choice in the postoperative care unit until the child is able to tolerate oral codeine. In addition we monitor all children with a diagnosis of OSAS with an Nellcor N200 oximeter (Nellcor, Pleasanton, CA, USA) on the first postoperative night. Postoperative events of interest included both respiratory complications and medical interventions. Postoperative respiratory desaturation was defined as a room air oxygen saturation less than 95\%. Administration of oxygen, insertion of an oropharyngeal airway, reintubation and ventilation were considered medical interventions.

\section{MEDICAL CHART REVIEW}

The children were divided into two groups based on the presence of postoperative desaturation into a desaturated (deSAT) or saturated (SAT) group. Desaturation which occurred before the child left the operating room, did not influence the grouping criteria.

Pertinent history, operative and postoperative information were recorded including the start time of the operative procedure. Outcome was assessed from written reports in the nursing and medical records. A review of medical charts was conducted for children in the deSAT group. The number of desaturations in the first $24 \mathrm{hr}$ postoperative period, as documented in the medical chart, were recorded by a pediatric anesthesiologist (A.K.). The clock time of opioid administration and the clock time at which a respiratory complication occurred were recorded. The temporal relationship between opioid administration and the first (postdeSAT ${ }_{1 s t}$ ) and minimum (postSaO $\mathrm{O}_{2}$ nadir) were determined. The "sleep state" reported in the nursing charts as "awake" or "asleep" at the time of desaturation was noted.

\section{RELATIONSHIP BETWEEN POSTOPERATIVE MOR- \\ PHINE ADMINISTRATION AND POSTOPERATIVE \\ DESATURATION}

Children who did not desaturate in the postoperative period (group SAT) were assigned a value for postSaO 2 nadir of $95 \%$. The difference between the postdeSAT $_{1 s t}$ and postSaO ${ }_{2}$ nadir was calculated. The time intervals: 1) between the postSaO $\operatorname{Sadir}_{1 \mathrm{st}}$ and opioid administration immediately preceding it (Interval $\left.{ }_{1 \mathrm{st}}\right)$; and 2 ) between the postSaO $\mathrm{S}_{2}$ nadir and 


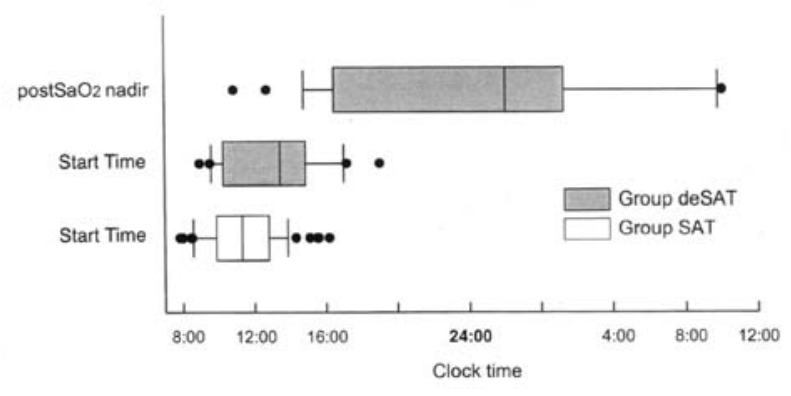

FIGURE Timing of events

Box plot distribution of data for the start time of surgery in group SAT and deSAT. Data is also given for the clock time at which the post oxygen saturation $\left(\mathrm{SaO}_{2}\right)$ nadir occurred in group deSAT. The median clock time for the post $\mathrm{SaO}_{2}$ nadir was 23:00 hr.

opioid administration immediately preceding the episode (Interval ${ }_{\text {nadir }}$ ) were calculated. Opioid dosing was converted to equianalgesic morphine doses, such that the relative potencies for codeine, fentanyl and sufentanil were $0.1,100$ and 1,000 respectively. ${ }^{14}$ The mean dose of opioid, administered in the initial three hours, was calculated as the sum of the intraoperative plus the first two postoperative hours (opioid-three hours) dose. The mean dose of opioid, administered in a 24-hr period during and following surgery (opioid-24) was also calculated.

\section{Statistical analysis}

The variables were analyzed using SAS for Windows (version 8.02, SAS Institute, Cary, NC, USA). Categorical data were summarized using frequencies and continuous variables were reported as mean \pm SD or ranges.

Known risk factors namely young age, a low oxygen saturation nadir and an associated medical condition, were categorized as age risk ( $<3 \mathrm{yr}$ or $\geq 3 \mathrm{yr}$ ), oxygen saturation $\left(\mathrm{SaO}_{2}\right)$ nadir risk $(<80 \%$ or $\geq 80 \%)$ and associated medical condition risk (yes $v s$ no) ${ }^{3,4}$ Surgery performed between 7:45 and 12:59 was designated morning (AM) and after 13:00 was designated afternoon (PM). The season for surgery performed between October and March was assigned to winter and for surgery performed between April and September was assigned to summer. Since the majority of children received postoperative opioids, opioid administration could not be evaluated as an independent risk factor. Opioid dosing, converted to morphine equivalents, was treated as a continuous variable.
The main outcome was the occurrence of desaturation following adenotonsillectomy. Risk factors were first evaluated with univariate analysis followed by multivariate logistic regression. ${ }^{15}$ Associations were tested by Chi squared statistics.

\section{Results}

There were 31 girls and 57 boys. The mean \pm SD age $(\mathrm{yr})$ and weight $(\mathrm{kg})$ were $4.6 \pm 2.9 \mathrm{yr}$ and $20.8 \pm 14.5$ $\mathrm{kg}$, respectively. Twenty-seven percent $(n=24)$ of children had an associated medical condition (asthma $=13$, cardiac $=2$, neuromuscular $=1$ ). The preopera tive $\mathrm{SaO}_{2}$ nadir was $77.1 \% \pm 13.9$ (range $20 \%-90 \%$ ). The preoperative $\mathrm{OAH}$ index was $21.5 \pm 22.0$ (range 5-142.2) events.hr-1.

The hospital stay was $38.6 \pm 34.9 \mathrm{hr}$. The minimum stay in hospital was eight hours. Sixty-six children were discharged prior to $24 \mathrm{hr}$ postoperatively. Four children were discharged the same day of surgery, $9.9 \pm 1.4 \mathrm{hr}$ after surgery. $\left(\mathrm{SaO}_{2}\right.$ nadir $=$ $82.8 \% \pm 12.7, \mathrm{OAH}$ index $=14.6 \pm 12.3$ events.hr $\left.{ }^{-1}\right)$. Sixty-two children were discharged the AM following surgery, mean stay in hospital was $23.4 \pm 9.4 \mathrm{hr}\left(\mathrm{SaO}_{2}\right.$ nadir $=79.0 \pm 12 \%, \mathrm{OAH}$ index $=16.2 \pm 10.7$ events.hr $\left.{ }^{-1}\right)$.

There were $63(71.6 \%)$ patients who did not experience postoperative desaturation (SAT group) and 25 (28.4\%) children who did (deSAT group). The distribution of known and potential risk factors is given in Table I. Differences in age, weight, gender and the presence of an associated medical condition were not significant. The preoperative $\mathrm{SaO}_{2}$ nadir for the SAT and deSAT groups was $80.8 \pm 10.2 \%$ and $67.6 \pm$ $17.5 \%$, respectively $(P<0.05)$. The preoperative $\mathrm{OAH}$ index was $15.8 \pm 10.2$ and $35.7 \pm 34.6$ events.hr ${ }^{-1}$, respectively $(P<0.05)$.

Surgery was performed in the winter season in 45 $(51 \%)$ children. The mean \pm SD duration of surgery was $49.1 \pm 11.5 \mathrm{~min}$. Differences in the duration of surgery were not significant. Surgery was performed in the AM in $63(71.6 \%)$ children. The time of surgery (24 hr clock) for groups SAT and deSAT was 11:24 \pm $2.03 \mathrm{hr}$ and 13:09 $\pm 2.7 \mathrm{hr}$, respectively.

The anesthetic technique varied. An iv induction was used in $62.5 \%$ of children $(n=55)$. Propofol was administered to 60 children whereas sodium pentothal was used in 18. Anesthesia was maintained with isoflurane $(n=23)$, halothane $(n=59)$ or sevoflurane $(n=$ 4 ) and unrecorded in two. The trachea of all children were intubated for the adenotonsillectomy. Atropine was administered at induction of anesthesia in $63 \%(n$ $=55$ ) of children. Non-opioid adjuncts were administered to 44 children (acetaminophen $=19$, ketorolac 
TABLE 1 Risk factors for postadenotonsillectomy desaturation

\begin{tabular}{llll}
\hline Risk factor & $\begin{array}{l}\text { Group deSAT } \\
(n=25)\end{array}$ & $\begin{array}{l}\text { GroupSAT } \\
(n=63)\end{array}$ & P-value \\
\hline Age & 10 & 19 & $\mathrm{NS}$ \\
$<3 \mathrm{yr}$ & 15 & 44 & \\
$\geq 3 \mathrm{yr}$ & 10 & 14 & $\mathrm{NS}$ \\
Associated medical condition & 49 & \\
Yes & 15 & & \\
$\mathrm{No}$ & 16 & 21 & $P<0.05$ \\
$\mathrm{SaO}$ nadir & 9 & 42 & \\
$<80 \%$ & & 12 & $P<0.05$ \\
$\geq 80 \%$ & 13 & 51 & \\
Clock time of surgery & & & \\
$\mathrm{PM}$ & 12 & 35 & $\mathrm{NS}$ \\
$\mathrm{AM}$ & 10 & 28 & \\
Time of year & 15 & & \\
Winter & & & \\
Summer & & & \\
\hline
\end{tabular}

Two by two Table for known (age, medical conditions, obstructive sleep apnea syndrome severity) and potential (time of day, season of year) risk factors. Differences in the preoperative $\mathrm{SaO}_{2}$ nadir during sleep and clock time of surgery were statistically significant by Chi squared analysis. $\mathrm{SaO}_{2}=$ oxygen saturation; $\mathrm{AM}=$ morning; $\mathrm{PM}=$ afternoon.

TABLE II Univariate analysis of risk factors for postadenotonsillectomy respiratory complications

\begin{tabular}{llll}
\hline $\begin{array}{l}\text { Potential risk factor } \\
\text { Age }\end{array}$ & OR & $95 \%$ CI & P-value \\
$\begin{array}{l}\text { Z yr vs }<3 \text { yr } \\
\text { Associated medical condition }\end{array}$ & 0.65 & $0.25-1.70$ & 0.376 \\
$\begin{array}{l}\text { yes vs no } \\
\text { SaO nadir }\end{array}$ & 2.33 & $0.86-6.32$ & 0.091 \\
$\quad<0 \%$ vs $\geq 80 \%$ & 3.56 & $1.35-9.38$ & 0.009 \\
$\begin{array}{l}\text { Time of year } \\
\text { Winter vs summer }\end{array}$ & 0.53 & $0.21-1.37$ & 0.188 \\
$\begin{array}{l}\text { Clock time of surgery } \\
\text { PM vs AM }\end{array}$ & 4.60 & $1.68-12.58$ & 0.002 \\
Opioid dose & 1.01 & $0.21-4.81$ & 0.993 \\
\hline
\end{tabular}

The odds ratio (OR) for a preoperative $\mathrm{SaO}_{2}$ nadir $<80 \%$ during sleep and surgery performed in the afternoon were significant risk factors by statistical criteria. Opioid dosing was treated as a continuous variable. $\mathrm{SaO}_{2}=$ oxygen saturation; $\mathrm{AM}=$ morning; $\mathrm{PM}=$ afternoon.

$=25)$. Seventy-one children received a muscle relaxant (atracurium $=1$, rocuronium $=43$, vecuronium $=13$, succinylcholine $=14)$. Thirty-seven $(65 \%)$ children who had received a nondepolarizing muscle relaxant did not receive a reversal agent. Seventy-six $(86.4 \%)$ children received an intraoperative opioid (morphine $=6$, fentanyl $=37$, sufentanil $=31$, codeine $=2$ ) . Differences in anesthetic management between the SAT and deSAT groups were not significant.
In the postoperative period 87 children received acetaminophen. Antiemetics were administered to a minority of children (droperidol $=4$, dimenhydrinate $=1$ ). Seven $(8 \%)$ children (group SAT $=3$, group deSAT $=4$ ) did not require any postoperative opioid in the first $24 \mathrm{hr}$. Sixty-nine (78.4\%) children received an opioid in the first two postoperative hours (morphine $=66$, meperidine $=1$, codeine $=2)$. Oral codeine was the most frequently administered opioid beyond the initial two postoperative hours $($ codeine $=$ 62 , morphine $=1$ ).

The main outcome was the occurrence of postoperative desaturation. Univariate analysis of $\mathrm{known}^{3,4}$ and potential risk factors identified two risk factors: the preoperative $\mathrm{SaO}_{2}$ nadir risk $(<80 \%$ vs $\geq 80 \%)$ and the time of day of surgery (PM vs AM; Table II). These risk factors remained significant when analyzed with a multivariate analysis. In addition, multivariate analysis gave an OR for the season (winter $v$ s summer) of $0.27,(95 \%$ confidence interval 0.08-0.94, $P=0.04$ ).

Secondary analysis of the mean number of desaturations recorded for the first postoperative 24-hr period, was $2.0 \pm 1.0$. Overall the value for the post $\mathrm{SaO}_{2}$ nadir was $16.2 \pm 13.0 \%$ higher than the $\mathrm{preSaO}_{2}$ nadir. The postdeSAT ${ }_{1 s t}$ and post $\mathrm{SaO}_{2}$ nadir were $90.4 \pm$ $4.3 \%$ and $88.6 \pm 4.6 \%$ respectively. The median clock time for the first and minimum desaturation was 17:30 and 23:00, respectively (Figure 1). The median time interval between surgery and respiratory complications was $3.3 \mathrm{hr}$ (range $67 \mathrm{~min}$ to $21 \mathrm{hr}$ ). The time interval between the first and minimum postoperative desaturation ranged from 0 to $13 \mathrm{hr}(2.5 \pm 3.8 \mathrm{hr})$. Eighteen $(72 \%)$ patients were asleep at the time of postdeSAT ${ }_{1 s t}$ and $21(84 \%)$ patients were asleep at the time of the post $\mathrm{SaO}_{2}$ nadir.

Four (16\%) patients had received no opioid prior to the postoperative desaturation. The mean dose for opioid-three hours (morphine equivalents, $\mathrm{mg} \cdot \mathrm{kg}^{-1}$ ) was $0.21 \pm 0.13$ and for opioid $24 \mathrm{hr}$ (morphine equivalents, $\mathrm{mg} \cdot \mathrm{kg}^{-1}$ ) was $0.48 \pm 0.30$. Differences in opioid dosing between groups SAT and deSAT were not significant. The time interval between opioid administration and the first postoperative desaturation was $4.2 \pm 4.5 \mathrm{hr}$ (range $0.5-17.3 \mathrm{hr}$ ).

The medical interventions required in the deSAT group were $\mathrm{O}_{2}$ administration $(n=25)$ and airway instrumentation (oropharyngeal airway $=2$, bag and mask ventilation $=4$, reintubation $=1$ ) .

\section{Discussion}

This report has several limitations inherent in a retrospective review. Recording of events may not be complete and it is likely that we under report the true incidence of 
desaturation. In addition, it was not possible to report reliable data on a history of recent upper airway infections, which might have influenced the occurrence of desaturation following surgery. ${ }^{16,17}$ We used a threshold of $95 \%$ to define postoperative desaturation, since this threshold is a criterion for discharge in our institution. Overall the postoperative saturation nadir increased $16 \%$ from the preoperative $\mathrm{SaO}_{2}$ nadir, a finding which is in agreement with that of Helfaer et al. ${ }^{18}$ However, one third of children in our study desaturated $<95 \%$ on the first postoperative night and were given $\mathrm{O}_{2}$.

Several factors may have contributed to desaturation in the postoperative period, including severity of OSAS, and the time of day at which surgery occurred.

\section{OSAS severity}

Although we sought to restrict the analysis to a homogenous population of children with severe OSAS, the fact that $\mathrm{preSaO}_{2}$ nadir was lower and the $\mathrm{OAH}$ index higher in the deSAT group suggests our population of severe OSAS was not as homogeneous a population as intended. In this regard, there is an emerging consensus that OSAS severity is an independent risk factor for respiratory morbidity. 3,4,18,19 Furthermore the criteria for stratification of OSAS disease severity for diagnosis and prediction of postoperative respiratory morbidity probably differ. As an example, the criterion for a diagnosis of severe OSAS is an OAH index $>5$ events.hr, ${ }^{-1}{ }^{20}$ whereas that for prediction of postadenotonsillectomy respiratory morbidity is an $\mathrm{OAH}$ index > 10 events.hr ${ }^{-1} .4$ There is a need to develop criteria applicable to an operative setting which define perioperative risk stratification in OSAS.

\section{Time of day of surgery}

Surgery performed in the AM in children with severe OSAS was associated with a lower risk for postoperative desaturation compared with those having their operation in the PM and we propose two explanations for this finding. First, children who are operated on in the AM have a longer time to recover from the effects of anesthesia before their first postoperative nocturnal sleep. Second, postoperative children may be better observed by day staff and alert parents early in the day.

The shortened time interval, between postoperative morphine dosing and bedtime, imposed by PM surgery may have contributed to the incidence of postoperative desaturation, given the exaggerated respiratory depression to opioids which has recently been reported in children with severe OSAS. ${ }^{21}$ It is noteworthy that the majority of desaturation (72\%) occurred during sleep. Pediatric OSAS is a disease of rapid eye movement (REM) sleep. Proportionally,
REM sleep increases and respiratory function is at its nadir, later in the sleep period. ${ }^{12,22}$ There is a strong possibility that the combination of opioids and sleep promote desaturation following adenotonsillectomy in children with severe OSAS.

A recent study reported that hospital admissions and surgeries performed on weekends were associated with a higher mortality than on weekdays, a finding attributed to lower staffing patterns on weekends. ${ }^{23}$ The median clock time at which the post $\mathrm{SaO}_{2}$ nadir occurred was 23:00 hr, coincident with the lowest staffing ratio. The child with severe OSAS may benefit from the close supervision afforded by a high nurse and physician staffing ratio.

\section{Conclusion}

Children with severe OSAS whose surgery is performed in the AM are less likely to desaturate following adenotonsillectomy than children whose surgery is performed in the PM. Surgery performed in the AM, could represent a cost-effective risk reduction strategy to decrease postadenotonsillectomy respiratory complications in children with severe OSAS which merits prospective study.

\section{References}

1 Rosenfeld RM, Green RP. Tonsillectomy and adenoidectomy: changing trends. Ann Otol Rhinol Laryngol 1990; 99: 187-91.

2 Pickering AE, Bridge HS, Nolan J, Stoddart PA. Double-blind, placebo-controlled analgesic study of ibuprofen or rofecoxib in combination with paracetamol for tonsillectomy in children. Br J Anaesth 2002; 88: 72-7.

3 Rosen GM, Muckle RP, Mabowald MW, Goding GS, Ullevig C. Postoperative respiratory compromise in children with obstructive sleep apnea syndrome: can it be anticipated? Pediatrics 1994; 93: 784-8.

4 McColley SA, April MM, Carroll JL, Naclerio RM, Loughlin GM. Respiratory compromise after adenotonsillectomy in children with obstructive sleep apnea. Arch Otolaryngol Head Neck Surg 1992; 118: 940-3.

5 Wilson K, Lakheeram I, Morielli A, Brouillette R, Brown K. Can assessment for obstructive sleep apnea help predict postadenotonsillectomy respiratory complications? Anesthesiology 2002; 96: 313-22.

6 Parnis SJ, Barker DS, Van Der Walt JH. Clinical predictors of anaesthetic complications in children with respiratory tract infections. Paediatr Anaesth 2001; 11: 29-40.

7 Newland MC, Ellis SJ, Lydiatt CA, et al. Anestheticrelated cardiac arrest and its mortality. A report covering 72,959 anesthetics over 10 years from US teaching 
hospitals. Anesthesiology 2002; 97: 108-15.

8 Katz ES, Greene MG, Carson KA, et al. Night-to-night variability of polysomnography in children with suspected obstructive sleep apnea. J Pediatr 2002; 140: 589-94.

9 Jacob SV, Morielli A, Mograss MA, Ducharme FM, Schloss MD, Brouillette RT. Home testing for pediatric obstructive sleep apnea syndrome secondary to adenotonsillar hypertrophy. Pediatr Pulmonol 1995; 20: 241-52.

10 Bronillette RT, Morielli A, Leimanis A, Waters KA, Luciano R, Ducharme FM. Nocturnal pulse oximetry as an abbreviated testing modality for pediatric obstructive sleep apnea. Pediatrics 2000; 105: 405-12.

11 Waters KA, Forbes P, Morielli A, et al. Sleep-disordered breathing in children with myelomeningocele. J Pediatr 1998; 132: 672-81.

12 Morielli A, Ladan S, Ducharme FM, Brouillette RT. Can sleep and wakefulness be distinguished in children by cardiorespiratory and videotape recordings? Chest 1996; 109: 680-7.

13 Lafontaine VM, Ducharme FM, Brouillette RT. Pulse oximetry: accuracy of methods of interpreting graphic summaries. Pediatr Pulmonol 1996; 21: 121-31.

14 Tobias JD. Pain management for the critically ill child in the pediatric intensive care unit. In: Schechter NL, Berde CB, Yaster M (Eds.). Pain in Infants, Children, and Adolescents, 2nd ed. Philadelphia, PA: Lippincott Williams \& Wilkins; 2003: 807-40.

15 Hosmer DW, Lemeshow S. Applied Logistic Regression, 2nd ed. New York: A Wiley-Interscience Publication; 2000.

16 Cohen MM, Cameron CB, Duncan PG. Pediatric anesthesia morbidity and mortality in the perioperative period. Anesth Analg 1990; 70: 160-7.

17 Cohen MM, Cameron CB. Should you cancel the operation when a child has an upper respiratory tract infection? Anesth Analg 1991; 72: 282-8.

18 Helfaer MA, McColley SA, Pyzik PL, et al.

Polysomnography after adenotonsillectomy in mild pediatric obstructive sleep apnea. Crit Care Med 1996; 24: 1323-7.

19 Suen JS, Arnold JE, Brooks LJ. Adenotonsillectomy for treatment of obstructive sleep apnea in children. Arch Otolaryngol Head Neck Surg 1995; 121: 525-30.

20 Marcus CL, Omlin KJ, Basinki DJ, et al. Normal polysomnographic values for children and adolescents. Am Rev Respir Dis 1992; 146: 1235-9.

21 Waters KA, McBrien F, Stewart P, Hinder M, Wharton $S$. Effects of OSA, inhalational anesthesia, and fentanyl on the airway and ventilation of children. J Appl Physiol 2002; 92: 1987-94.

22 Goh DY, Galster P, Marcus CL. Sleep architecture and respiratory disturbances in children with obstructive sleep apnea. Am J Respir Crit Care Med 2000; 162: 682-6.

23 Bell CM, Redelmeier DA. Mortality among patients admitted to hospitals on weekends as compared with weekdays. N Engl J Med 2001; 345: 663-8. 